BMJ Open

Sport \&

Exercise

Medicine

\title{
Considerations for the development of extreme heat policies in sport and exercise
}

To cite: Chalmers $S$, Anderson G, Jay 0 . Considerations for the development of extreme heat policies in sport and exercise. BMJ Open Sport \& Exercise Medicine 2020;6:e000774. doi:10.1136/ bmjsem-2020-000774

\section{SLinked}

- http://dx.doi.org/10.1136/ bmjsem-2019-000591

Check for updates

(C) Author(s) (or their employer(s)) 2020. Re-use permitted under CC BY-NC. No commercial re-use. See rights and permissions. Published by BMJ.

${ }^{1}$ Alliance for Research in Exercise, Nutrition, and Activity (ARENA), University of South Australia, Adelaide, South Australia, Australia

${ }^{2}$ Thermal Ergonomics Laboratory, The University of Sydney, Sydney School of Health Sciences, Sydney, New South Wales, Australia

${ }^{3}$ Charles Perkins Centre, The University of Sydney, Sydney, New South Wales, Australia

\section{Correspondence to} Dr Ollie Jay; ollie.jay@sydney.edu.au

\author{
Samuel Chalmers (D) ,", Glenda Anderson (D) ," Ollie Jay (D) ${ }^{2,3}$
}

\begin{abstract}
We detail key considerations for the development of extreme heat policies in sport and exercise. Policies should account for the four environmental parameters (ambient temperature, humidity, air velocity, and mean radiant temperature) and two personal (activity and clothing) parameters that determine the prevailing thermoregulatory strain during exercise in the heat. Considerations for how to measure environmental stress and convey the level of risk are discussed. Finally, we highlight the need to include feasible cooling strategies that are relevant for the prevailing environmental conditions.
\end{abstract}

The paper by Gamage et al provides a current overview of public sport heat policies in a state (Victoria) of Australia. The review highlighted the lack of consistent content among policies, and the incompleteness of many documents, concluding that many organisations need to urgently update their policies. In light of these findings, we aim to highlight factors that should be considered in designing a modern comprehensive heat policy.

\section{WHAT WE SHOULD MEASURE, AND HOW WE SHOULD MEASURE IT}

The fundamental laws of human heat balance state that internal body heat storage and associated risk of substantial rises in core temperature occurs when the rate of internal heat generation (ie, metabolic rate - external work) consistently exceeds the net heat loss achieved via the four heat transfer (gain or loss) avenues of radiative, convective, conduction and evaporative. ${ }^{2}$ There are four environmental parameters that influence heat transfer and subsequent body heat storage: ambient temperature, humidity (absolute), air velocity and mean radiant temperature. Ambient temperature in isolation has long been relied on as an answer to the seemingly straightforward question of 'is it too hot to play today?'. Reviews by both Gamage et $a l^{1}$ and Chalmers and Jay ${ }^{3}$ highlighted the substantial reliance on ambient temperature alone to guide heat policies in Australian sport and exercise communities. While some policies extend beyond just ambient temperature, rarely do policies directly consider all four environmental parameters that determine the rate of heat transfer. Particularly, air velocity and thermal radiation (which is typically from solar sources) are often neglected. Air velocity influences the rate of convective (gain or loss) and evaporative heat transfer, with a low air velocity supressing heat loss during sport in most environments, but not all. ${ }^{4}$ Solar radiation is important to assess if events are conducted outdoors because ambient temperature is only representative of shaded areas. For example, the globe temperature can be $>15^{\circ} \mathrm{C}$ warmer than temperature in the shade.

Second, there are two personal parameters that also contribute towards determining heat storage: activity and clothing. These factors are also often neglected in public heat policies. The human body is inefficient during movement, with typically $>70 \%-$ $90 \%$ of energy liberated internally as heat, even during a relatively efficient task such as cycling. ${ }^{5}$ A common issue in sport and exercise communities is the adoption of a common broad policy that is not specific to a type of activity, and this was highlighted by Gamage et $a l .{ }^{1}$ We reported recently that some golfing and netball organisations in Australia defer to broad guidelines by an independent organisation, even though the estimated metabolic rate is twice as high in netball. ${ }^{3}$ Sport-specific clothing impacts the thermal response to activity through differences in insulative, vapour resistance and air permeability properties. ${ }^{2}$ Gamage et $a l^{1}$ advocate the consideration of personal factors, but ultimately, highly specialised skills are required to model the level of risk while including these factors (see Havenith and Fiala ${ }^{2}$ for comprehensive review). Therefore, sporting organisations must choose between commissioning a specialist or adopting generic guidelines. 
Organisations have two options for measuring environmental stress: (1) acquire publicly available weather data or (2) monitor local conditions using specialised equipment. The former option is affordable and now more accessible than ever due to hyperlocal open-access data on websites. Cost has been previously identified as a substantial barrier to the implementation of heat policies, ${ }^{6}$ which makes the former option attractive. However, the applicability of the data needs to be scrutinised by the organisation based on the type of equipment and locality of the nearest weather station to the event and the potential presence of local microclimates that may not be represented by weather station data collected in different settings although close-by. It has been reported that local weather stations (within $13 \mathrm{~km}$ ) consistently underestimate the actual on-field/court heat stress, often relating to the specificity of the event location (ie, stadium, surface type and other structures). ${ }^{7}$ Moreover, any indirect estimation of a unified index (eg, Wet-bulb globe temperature (WBGT), see below) that does not employ any direct measurement of thermal radiation is greatly limited." ${ }^{2}$. The latter option provides the best representation of environmental conditions experienced by individuals at the event, but the design, and therefore validity, of the equipment must be considered. For example, many common portable wet-bulb globe temperature monitors have black globes that are smaller than the standard size $(150 \mathrm{~mm})$, and therefore, readings must be treated with some caution. ${ }^{2}$

\section{Rating and communicating the level of risk}

A heat policy should be easy to interpret for the end-user. A limitation of the current Sports Medicine Australia policy is the uncertainty of how to categorise the overall level of risk for the prevailing conditions when the ambient temperature and relative humidity independently fall within separate risk categories. A heat policy should have a continuous scale of risk categories rather than just a simple dichotomous 'cancellation' threshold. Evidencebased progressive risk mitigation strategies should be included at each of these levels (discussed below). From a pragmatic perspective, the cancellation threshold should not overprotect individuals, otherwise there is a risk of organisations simply ignoring the policy altogether. ${ }^{3}$ Organisations must also consider the level of specificity for individuals of different age ranges and physical function. Recent evidence suggests that children may not have impairments in thermoregulatory function per se, but rather behavioural and educative guidelines are essential for reducing the risk of heat illness. ${ }^{8}$ Loss of physiological function (via a spinal cord injury) has also been shown to inhibit heat loss potential, with the extent based on the severity of injury. ${ }^{9}$

Some sporting organisations have adopted consolidated environmental stress scales that directly or indirectly account for all four environmental factors, such as the commonly used WBGT. ${ }^{10}$ While the WBGT has been a positive tool for rating and communicating the level of risk and reducing the risk of heat illness, it is important to acknowledge that it is only a marker of environmental stress. The level of risk under the prevailing conditions will be different for a range of sports because of different personal parameters (activity and clothing). Sport-specific modelling that considers all environmental and personal factors would potentially overcome this limitation. Ideally, a policy based on sport-specific modelling or the use of existing environmental stress markers (WBGT and heat index) should be validated by observing indicators of environmental strain (core temperature and sweat rate) in a field or laboratory-based setting. ${ }^{2}$

\section{RISK MITIGATION STRATEGIES}

Acclimatising to the heat and adequate hydration practices have long been considered the gold-standard strategies for reducing the risk of heat illness. ${ }^{11}$ However, it should be considered that systematic acclimation training is not feasible for many individuals. Sporting activities that inherently incur substantial dehydration will likely require participants to develop an evidencebased hydration plan, as opposed to ad libitum fluid consumption. ${ }^{12}$

Gamage et al highlighted that sporting heat policies in Victoria (Australia) rarely address cooling strategies, perhaps due to the preoccupation placed on acclimatisation and hydration. Within-event cooling strategies that have been shown to be effective in different sporting (laboratory or field) contexts include: cold water/ice slurry ingestion, ${ }^{13}$ iced garments (such as towels) ${ }^{14}$ fans (most often with additional skin wetting $)^{15}$ and additional in-game breaks. ${ }^{16}$ Policy makers should be aware that these cooling strategies are often environment specific. For example, the ingestion of cold water/ice slurry will not result in a net body cooling effect in all environments (due to a resultant blunting of sweat drive and evaporation ${ }^{13}$ while similarly, a fan in isolation may not promote a net cooling effect in a very hot and dry environment (due to promoting additional convective heat gain). ${ }^{14} 17$ The implementation of within-event cooling strategies should be chosen in the context of the sport (ie, pragmatics) and the prevailing level of environmental stress. Cold-water immersion is generally considered the preferred method for substantially and quickly cooling an individual with a high core temperature once they are removed (either through finishing or experiencing health concerns) from the event. ${ }^{18}$

In conclusion, collaboration among key stakeholders is crucial for the successful implementation and adherence to a heat policy. ${ }^{6}$ The redevelopment of the Cricket Australia extreme heat policy is a case example of bringing these implementation and methodological considerations together that ultimately provides highquality protection for individuals. ${ }^{19}$

Contributors All authors contributed to all aspects of the manuscript.

Funding The authors have not declared a specific grant for this research from any funding agency in the public, commercial or not-for-profit sectors. 
Competing interests None declared.

Patient consent for publication Not required.

Provenance and peer review Commissioned; externally peer reviewed.

Open access This is an open access article distributed in accordance with the Creative Commons Attribution Non Commercial (CC BY-NC 4.0) license, which permits others to distribute, remix, adapt, build upon this work non-commercially, and license their derivative works on different terms, provided the original work is properly cited, appropriate credit is given, any changes made indicated, and the use is non-commercial. See: http://creativecommons.org/licenses/by-nc/4.0/.

\section{ORCID iDs}

Samuel Chalmers http://orcid.org/0000-0003-1901-6910

Glenda Anderson http://orcid.org/0000-0001-5811-0796

Ollie Jay http://orcid.org/0000-0002-6076-6337

\section{REFERENCES}

1 Gamage PJ, Finch CF, Fortington LV. Document analysis of exertional heat illness policies and guidelines published by sports organisations in Victoria, Australia. BMJ Open Sport Exerc Med. 2020.

2 Havenith G, Fiala D. Thermal indices and thermophysiological modeling for heat stress. Compr Physiol 2016;6:255-302.

3 Chalmers S, Jay O. Australian community sport extreme heat policies: limitations and opportunities for improvement. J Sci Med Sport 2018;21:544-8

4 Deren TM, Coris EE, Casa DJ, et al. Maximum heat loss potential is lower in football linemen during an NCAA summer training CAMP because of lower self-generated air flow. J Strength Cond Res 2014;28:1656-63.

5 Gaesser GA, Tucker WJ, Sawyer BJ, et al. Cycling efficiency and energy cost of walking in young and older adults. J Appl Physiol 2018;124:414-20.

6 Pike AM, Adams WM, Huggins RA, et al. Analysis of states' barriers to and progress toward implementation of health and safety policies for secondary school athletics. J Athl Train 2019;54:361-73.
7 Pryor JL, Pryor RR, Grundstein A, et al. The heat strain of various athletic surfaces: a comparison between observed and modeled wet-bulb globe temperatures. J Athl Train 2017;52:1056-64.

8 Council on Sports Medicine and Fitness and Council on School Health, Bergeron MF, Devore C, et al. Policy statement-Climatic heat stress and exercising children and adolescents. Pediatrics 2011;128:e741-5.

9 Forsyth P, Miller J, Pumpa K, et al. Independent influence of spinal cord injury level on thermoregulation during exercise. Med Sci Sports Exerc 2019;51:1710-9.

10 Armstrong LE, Casa DJ, Millard-Stafford M, et al. Exertional heat illness during training and competition. Med Sci Sports Exerc 2007;39:556-72.

11 Racinais S, Alonso JM, Coutts AJ, et al. Consensus recommendations on training and competing in the heat. Scand $J$ Med Sci Sports 2015;25:6-19.

12 Kenefick RW. Drinking strategies: planned drinking versus drinking to thirst. Sports Med 2018;48:31-7.

13 Jay $\mathrm{O}$, Morris NB. Does cold water or ice slurry ingestion during exercise elicit a net body cooling effect in the heat? Sports Med 2018;48:17-29.

14 Lynch GP, Périard JD, Pluim BM, et al. Optimal cooling strategies for players in Australian tennis open conditions. J Sci Med Sport 2018;21:232-7.

15 Schranner D, Scherer L, Lynch GP, et al. In-play cooling interventions for simulated match-play tennis in hot/humid conditions. Med Sci Sports Exerc 2017;49:991-8.

16 Chalmers S, Siegler J, Lovell R, et al. Brief in-play cooling breaks reduce thermal strain during football in hot conditions. J Sci Med Sport 2019;22:912-7.

17 Morris NB, English T, Hospers L, et al. The effects of electric fan use under differing resting heat index conditions: a clinical trial. Ann Intern Med 2019:675-3.

18 Zhang Y, Davis J-K, Casa DJ, et al. Optimizing cold water immersion for exercise-induced hyperthermia: a meta-analysis. Med Sci Sports Exerc 2015;47:2464-72.

19 University of Leeds, British Association for Sustainable Sport, University of Portsmouth. Hit for six: the impact of climate change on cricket, 2019. Available: https://basis.org.uk/2019/09/hit-for-sixreport/ 